\title{
Some results on asymptotically quasi- $\phi$-nonexpansive mappings in the intermediate sense and equilibrium problems
}

\author{
Chunyan Huang ${ }^{1}$ and Xiaoyan $\mathrm{Ma}^{2^{*}}$
}

\footnotetext{
"Correspondence: kfmaxy@yeah.net ${ }^{2}$ Basic Experimental \& Teaching Center, Henan University, Kaifeng Henan, China

Full list of author information is available at the end of the article
}

\begin{abstract}
In this paper, we investigate a common fixed point problem of a finite family of asymptotically quasi- $\phi$-nonexpansive mappings in the intermediate sense and an equilibrium problem. Strong convergence theorems of common solutions are established in a uniformly smooth and strictly convex Banach space which also enjoys the Kadec-Klee property.

MSC: 47H09; 47J25; 90C33

Keywords: asymptotically quasi- $\phi$-nonexpansive mapping; asymptotically quasi- $\phi$-nonexpansive mapping in the intermediate sense; generalized projection; equilibrium problem; fixed point
\end{abstract}

\section{Introduction-preliminaries}

Let $E$ be a real Banach space. Recall that $E$ is said to be strictly convex if $\left\|\frac{x+y}{2}\right\|<1$ for all $x, y \in E$ with $\|x\|=\|y\|=1$ and $x \neq y$. It is said to be uniformly convex if $\lim _{n \rightarrow \infty}\left\|x_{n}-y_{n}\right\|=0$ for any two sequences $\left\{x_{n}\right\}$ and $\left\{y_{n}\right\}$ in $E$ such that $\left\|x_{n}\right\|=\left\|y_{n}\right\|=1$ and $\lim _{n \rightarrow \infty}\left\|\frac{x_{n}+y_{n}}{2}\right\|=1$. Let $U_{E}=\{x \in E:\|x\|=1\}$ be the unit sphere of $E$. Then the Banach space $E$ is said to be smooth if

$$
\lim _{t \rightarrow 0} \frac{\|x+t y\|-\|x\|}{t}
$$

exists for each $x, y \in U_{E}$. It is said to be uniformly smooth if the above limit is attained uniformly for $x, y \in U_{E}$.

Recall that $E$ has Kadec-Klee property if for any sequence $\left\{x_{n}\right\} \subset E$, and $x \in E$ with $x_{n} \rightarrow x$, and $\left\|x_{n}\right\| \rightarrow\|x\|$, then $\left\|x_{n}-x\right\| \rightarrow 0$ as $n \rightarrow \infty$. For more details of the KadecKlee property, the readers can refer to [1] and the references therein. It is well known that if $E$ is a uniformly convex Banach space, then $E$ enjoys the Kadec-Klee property.

Recall that the normalized duality mapping $J$ from $E$ to $2^{E^{*}}$ is defined by

$$
J x=\left\{f^{*} \in E^{*}:\left\langle x, f^{*}\right\rangle=\|x\|^{2}=\left\|f^{*}\right\|^{2}\right\}
$$

where $\langle\cdot, \cdot\rangle$ denotes the generalized duality pairing. It is well known that if $E$ is uniformly smooth, then $J$ is uniformly norm-to-norm continuous on each bounded subset of $E$. It is also well known that if $E$ is uniformly smooth if and only if $E^{*}$ is uniformly convex.

○2014 Huang and Ma; licensee Springer. This is an Open Access article distributed under the terms of the Creative Commons Attribution License (http://creativecommons.org/licenses/by/2.0), which permits unrestricted use, distribution, and reproduction in any medium, provided the original work is properly cited. 
Next, we assume that $E$ is a smooth Banach space. Consider the functional defined by

$$
\phi(x, y)=\|x\|^{2}-2\langle x, J y\rangle+\|y\|^{2}, \quad \forall x, y \in E .
$$

Observe that, in a Hilbert space $H$, the equality is reduced to $\phi(x, y)=\|x-y\|^{2}, x, y \in H$. As we all know if $C$ is a nonempty closed convex subset of a Hilbert space $H$ and $P_{C}$ : $H \rightarrow C$ is the metric projection of $H$ onto $C$, then $P_{C}$ is nonexpansive. This fact actually characterizes Hilbert spaces and consequently, it is not available in more general Banach spaces. In this connection, Alber [2] recently introduced a generalized projection operator $\Pi_{C}$ in a Banach space $E$ which is an analog of the metric projection $P_{C}$ in Hilbert spaces. Recall that the generalized projection $\Pi_{C}: E \rightarrow C$ is a map that assigns to an arbitrary point $x \in E$ the minimum point of the functional $\phi(x, y)$, that is, $\Pi_{C} x=\bar{x}$, where $\bar{x}$ is the solution to the minimization problem

$$
\phi(\bar{x}, x)=\min _{y \in C} \phi(y, x)
$$

The existence and uniqueness of the operator $\Pi_{C}$ follow from the properties of the functional $\phi(x, y)$ and strict monotonicity of the mapping $J$; see, for example, $[1,2]$. In Hilbert spaces, $\Pi_{C}=P_{C}$. It is obvious from the definition of the function $\phi$ that

$$
(\|x\|-\|y\|)^{2} \leq \phi(x, y) \leq(\|y\|+\|x\|)^{2}, \quad \forall x, y \in E,
$$

and

$$
\phi(x, y)=\phi(x, z)+\phi(z, y)+2\langle x-z, J z-J y\rangle, \quad \forall x, y, z \in E .
$$

Remark 1.1 If $E$ is a reflexive, strictly convex, and smooth Banach space, then $\phi(x, y)=0$ if and only if $x=y$; for more details, see $[1,2]$ and the references therein.

Let $C$ be a nonempty subset of $E$ and let $T: C \rightarrow C$ be a mapping. In this paper, we use $F(T)$ to denote the fixed point set of $T$. $T$ is said to be asymptotically regular on $C$ if for any bounded subset $K$ of $C$,

$$
\limsup _{n \rightarrow \infty}\left\{\left\|T^{n+1} x-T^{n} x\right\|: x \in K\right\}=0 .
$$

$T$ is said to be closed if for any sequence $\left\{x_{n}\right\} \subset C$ such that $\lim _{n \rightarrow \infty} x_{n}=x_{0}$ and $\lim _{n \rightarrow \infty} T x_{n}=y_{0}$, then $T x_{0}=y_{0}$. In this paper, we use $\rightarrow$ and $\rightarrow$ to denote the strong convergence and weak convergence, respectively.

Recall that a point $p$ in $C$ is said to be an asymptotic fixed point of $T$ [3] iff $C$ contains a sequence $\left\{x_{n}\right\}$ which converges weakly to $p$ such that $\lim _{n \rightarrow \infty}\left\|x_{n}-T x_{n}\right\|=0$. The set of asymptotic fixed points of $T$ will be denoted by $\widetilde{F}(T)$.

A mapping $T$ is said to be relatively nonexpansive iff

$$
\widetilde{F}(T)=F(T) \neq \emptyset, \quad \phi(p, T x) \leq \phi(p, x), \quad \forall x \in C, \forall p \in F(T) .
$$


A mapping $T$ is said to be relatively asymptotically nonexpansive iff

$$
\widetilde{F}(T)=F(T) \neq \emptyset, \quad \phi\left(p, T^{n} x\right) \leq\left(1+\mu_{n}\right) \phi(p, x), \quad \forall x \in C, \forall p \in F(T), \forall n \geq 1,
$$

where $\left\{\mu_{n}\right\} \subset[0, \infty)$ is a sequence such that $\mu_{n} \rightarrow 0$ as $n \rightarrow \infty$.

Remark 1.2 The class of relatively asymptotically nonexpansive mappings were first considered in [4]; see also, [5] and the references therein.

Recall that a mapping $T$ is said to be quasi- $\phi$-nonexpansive iff

$$
F(T) \neq \emptyset, \quad \phi(p, T x) \leq \phi(p, x), \quad \forall x \in C, \forall p \in F(T) .
$$

Recall that a mapping $T$ is said to be asymptotically quasi- $\phi$-nonexpansive iff there exists a sequence $\left\{\mu_{n}\right\} \subset[0, \infty)$ with $\mu_{n} \rightarrow 0$ as $n \rightarrow \infty$ such that

$$
F(T) \neq \emptyset, \quad \phi\left(p, T^{n} x\right) \leq\left(1+\mu_{n}\right) \phi(p, x), \quad \forall x \in C, \forall p \in F(T), \forall n \geq 1 .
$$

Remark 1.3 The class of quasi- $\phi$-nonexpansive mappings was considered in [6]. The class of asymptotically quasi- $\phi$-nonexpansive mappings which was investigated in [7] and [8] includes the class of quasi- $\phi$-nonexpansive mappings as a special case.

Remark 1.4 The class of quasi- $\phi$-nonexpansive mappings and the class of asymptotically quasi- $\phi$-nonexpansive mappings are more general than the class of relatively nonexpansive mappings and the class of relatively asymptotically nonexpansive mappings. Quasi$\phi$-nonexpansive mappings and asymptotically quasi- $\phi$-nonexpansive do not require the restriction $F(T)=\widetilde{F}(T)$.

Remark 1.5 The class of quasi- $\phi$-nonexpansive mappings and the class of asymptotically quasi- $\phi$-nonexpansive mappings are generalizations of the class of quasi-nonexpansive mappings and the class of asymptotically quasi-nonexpansive mappings in Banach spaces.

Recall that $T$ is said to be asymptotically quasi- $\phi$-nonexpansive in the intermediate sense iff $F(T) \neq \emptyset$ and the following inequality holds:

$$
\limsup _{n \rightarrow \infty} \sup _{p \in F(T), x \in C}\left(\phi\left(p, T^{n} x\right)-\phi(p, x)\right) \leq 0 .
$$

Putting

$$
\xi_{n}=\max \left\{0, \sup _{p \in F(T), x \in C}\left(\phi\left(p, T^{n} x\right)-\phi(p, x)\right)\right\},
$$

it follows that $\xi_{n} \rightarrow 0$ as $n \rightarrow \infty$. Then (1.3) is reduced to the following:

$$
\phi\left(p, T^{n} x\right) \leq \phi(p, x)+\xi_{n}, \quad \forall p \in F(T), \forall x \in C .
$$

Remark 1.6 The class of asymptotically quasi- $\phi$-nonexpansive mappings in the intermediate sense was first considered by Qin and Wang [9]. 
Remark 1.7 The class of asymptotically quasi- $\phi$-nonexpansive mappings in the intermediate sense is a generalization of the class of asymptotically quasi-nonexpansive mappings in the intermediate sense, which was considered by Kirk [10], in the framework of Banach spaces.

Let $f$ be a bifunction from $C \times C$ to $\mathbb{R}$, where $\mathbb{R}$ denotes the set of real numbers. Recall the following equilibrium problem. Find $p \in C$ such that

$$
f(p, y) \geq 0, \quad \forall y \in C
$$

We use $E P(f)$ to denote the solution set of the equilibrium problem (1.5). That is,

$$
E P(f)=\{p \in C: f(p, y) \geq 0, \forall y \in C\} .
$$

We remark here that the equilibrium problem was first introduced by Fan [11]. Given a mapping $Q: C \rightarrow E^{*}$, let

$$
f(x, y)=\langle Q x, y-x\rangle, \quad \forall x, y \in C
$$

Then $p \in E P(f)$ if and only if $p$ is a solution of the following variational inequality. Find $p$ such that

$$
\langle Q p, y-p\rangle \geq 0, \quad \forall y \in C
$$

To study the equilibrium problems (1.5), we may assume that $F$ satisfies the following conditions:

(A1) $F(x, x)=0$ for all $x \in C$;

(A2) $F$ is monotone, i.e., $F(x, y)+F(y, x) \leq 0$ for all $x, y \in C$;

(A3) for each $x, y, z \in C$,

$$
\limsup _{t \downarrow 0} F(t z+(1-t) x, y) \leq F(x, y)
$$

(A4) for each $x \in C, y \mapsto F(x, y)$ is convex and weakly lower semi-continuous.

Numerous problems in physics, optimization, and economics reduce to find a solution of (1.5). Recently, many authors have investigated common solutions of fixed point and equilibrium problems in Banach spaces; see, for example, [12-33] and the references therein.

In this paper, we consider a projection algorithm for treating the equilibrium problem and fixed point problems of asymptotically quasi- $\phi$-nonexpansive mappings in the intermediate sense.

In order to prove our main results, we need the following lemmas.

Lemma 1.8 [2] Let E be a reflexive, strictly convex and smooth Banach space. Let $C$ be a nonempty closed convex subset of $E$ and let $x \in E$. Then

$$
\phi\left(y, \Pi_{C} x\right)+\phi\left(\Pi_{C} x, x\right) \leq \phi(y, x), \quad \forall y \in C .
$$


Lemma 1.9 [2] Let C be a nonempty closed convex subset of a smooth Banach space E and let $x \in E$. Then $x_{0}=\Pi_{C} x$ if and only if

$$
\left\langle x_{0}-y, J x-J x_{0}\right\rangle \geq 0, \quad \forall y \in C .
$$

Lemma 1.10 Let $C$ be a closed convex subset of a smooth, strictly convex and reflexive Banach space E. Let $f$ be a bifunction from $C \times C$ to $\mathbb{R}$ satisfying (A1)-(A4). Let $r>0$ and $x \in E$. Then

(a) [34] There exists $z \in C$ such that

$$
f(z, y)+\frac{1}{r}\langle y-z, J z-J x\rangle \geq 0, \quad \forall y \in C .
$$

(b) [6, 24] Define a mapping $T_{r}: E \rightarrow C$ by

$$
S_{r} x=\left\{z \in C: f(z, y)+\frac{1}{r}\langle y-z, J z-J x\rangle, \forall y \in C\right\} .
$$

Then the following conclusions hold:

(1) $S_{r}$ is single-valued;

(2) $S_{r}$ is a firmly nonexpansive-type mapping, i.e., for all $x, y \in E$,

$$
\left\langle S_{r} x-S_{r} y, J S_{r} x-J S_{r} y\right\rangle \leq\left\langle S_{r} x-S_{r} y, J x-J y\right\rangle
$$

(3) $F\left(S_{r}\right)=E P(f)$;

(4) $S_{r}$ is quasi- $\phi$-nonexpansive;

(5) $\phi\left(q, S_{r} x\right)+\phi\left(S_{r} x, x\right) \leq \phi(q, x), \forall q \in F\left(S_{r}\right)$;

(6) $E P(f)$ is closed and convex.

Lemma 1.11 [35] Let E be a smooth and uniformly convex Banach space and let $r>0$. Then there exists a strictly increasing, continuous and convex function $g:[0,2 r] \rightarrow R$ such that $g(0)=0$ and

$$
\|t x+(1-t) y\|^{2} \leq t\|x\|^{2}+(1-t)\|y\|^{2}-t(1-t) g(\|x-y\|)
$$

for all $x, y \in B_{r}=\{x \in E:\|x\| \leq r\}$ and $t \in[0,1]$

\section{Main results}

Theorem 2.1 Let E be a uniformly smooth and strictly convex Banach space which also enjoys the Kadec-Klee property and let $C$ be a nonempty closed and convex subset of E. Letf be a bifunction from $C \times C$ to $\mathbb{R}$ satisfying (A1)-(A4) and let $N$ be some positive integer. Let $T_{i}: C \rightarrow C$ an asymptotically quasi- $\phi$-nonexpansive mapping in the intermediate sense for every $1 \leq i \leq N$. Assume that $T_{i}$ is closed asymptotically regular on $C$ and $\bigcap_{i=1}^{N} F\left(T_{i}\right) \cap$ 
$E F(f)$ is nonempty and bounded. Let $\left\{x_{n}\right\}$ be a sequence generated in the following manner:

$$
\left\{\begin{array}{l}
x_{0} \in E \text { chosen arbitrarily, } \\
C_{1}=C, \\
x_{1}=\Pi_{C_{1} x_{0}}, \\
y_{n}=J^{-1}\left(\alpha_{n, 0} J x_{n}+\sum_{i=1}^{N} \alpha_{n, j} J T_{i}^{n} x_{n}\right), \\
u_{n} \in C \text { such that } f\left(u_{n}, y\right)+\frac{1}{r_{n}}\left\langle y-u_{n}, J u_{n}-J y_{n}\right\rangle \geq 0, \quad \forall y \in C, \\
C_{n+1}=\left\{z \in C_{n}: \phi\left(z, u_{n}\right) \leq \phi\left(z, x_{n}\right)+\xi_{n}\right\}, \\
x_{n+1}=\Pi_{C_{n+1}} x_{0},
\end{array}\right.
$$

where $\xi_{n}=\max \left\{0, \sup _{p \in F\left(T_{i}\right), x \in C}\left(\phi\left(p, T_{i}^{n} x\right)-\phi(p, x)\right)\right\},\left\{\alpha_{n, i}\right\}$ is a real number sequence in $(0,1)$ for every $1 \leq i \leq N,\left\{r_{n}\right\}$ is a real number sequence in $[k, \infty)$, where $k$ is some positive real number. Assume that $\sum_{i=0}^{N} \alpha_{n, i}=1$ and $\liminf _{n \rightarrow \infty} \alpha_{n, 0} \alpha_{n, i}>0$ for every $1 \leq i \leq N$. Then the sequence $\left\{x_{n}\right\}$ converges strongly to $\Pi_{\bigcap_{i=1}^{N} F\left(T_{i}\right) \cap E F(f)} x_{1}$, where $\prod_{\bigcap_{i=1}^{N} F\left(T_{i}\right) \cap E F(f)}$ is the generalized projection from $E$ onto $\bigcap_{i=1}^{N} F\left(T_{i}\right) \cap E F(f)$.

Proof First, we show that $\bigcap_{i=1}^{N} F\left(T_{i}\right) \cap E F(f)$ is closed and convex. From [9], we find that $\bigcap_{i=1}^{N} F\left(T_{i}\right)$ is closed and convex, which combines with Lemma 1.10 shows that $\bigcap_{i=1}^{N} F\left(T_{i}\right) \cap$ $E F(f)$ is closed and convex. Next, we show that $C_{n}$ is closed and convex. It is obvious that $C_{1}=C$ is closed and convex. Suppose that $C_{h}$ is closed and convex for some positive integer $h$. For $z \in C_{h}$, we see that $\phi\left(z, u_{h}\right) \leq \phi\left(z, x_{h}\right)+\xi_{h}$ is equivalent to

$$
2\left\langle z, J x_{h}-J u_{h}\right\rangle \leq\left\|x_{k}\right\|^{2}-\left\|u_{k}\right\|^{2}+\xi_{h}
$$

It is to see that $C_{h+1}$ is closed and convex. This proves that $C_{n}$ is closed and convex. This in turn shows that $\Pi_{C_{n+1}} x_{1}$ is well defined. Putting $u_{n}=S_{r_{n}} y_{n}$, we from Lemma 1.10 see that $S_{r_{n}}$ is quasi- $\phi$-nonexpansive. Now, we are in a position to prove that $\bigcap_{i=1}^{N} F\left(T_{i}\right) \cap E F(f) \subset C_{n}$. Indeed, $\bigcap_{i=1}^{N} F\left(T_{i}\right) \cap E F(f) \subset C_{1}=C$ is obvious. Assume that $\bigcap_{i=1}^{N} F\left(T_{i}\right) \cap E F(f) \subset C_{h}$ for some positive integer $h$. Then, for $\forall w \in \bigcap_{i=1}^{N} F\left(T_{i}\right) \cap E F(f) \subset C_{h}$, we have

$$
\begin{aligned}
\phi\left(w, u_{h}\right) & =\phi\left(w, S_{r_{h}} y_{h}\right) \\
& \leq \phi\left(w, y_{h}\right) \\
& =\phi\left(w, J^{-1}\left(\alpha_{h, 0} J x_{h}+\sum_{i=1}^{N} \alpha_{h, i} J T_{i}^{h} x_{h}\right)\right) \\
& =\|w\|^{2}-2\left\langle w, \alpha_{h, 0} J x_{h}+\sum_{i=1}^{N} \alpha_{h, i} J T_{i}^{h} x_{h}\right\rangle+\left\|\alpha_{h, 0} J x_{h}+\sum_{i=1}^{N} \alpha_{h, i} J T_{i}^{h} x_{h}\right\|^{2} \\
& \leq\|w\|^{2}-2 \alpha_{h, 0}\left\langle w, J x_{h}\right\rangle-2 \sum_{i=1}^{N} \alpha_{h, i}\left\langle w, J T_{i}^{h} x_{h}\right\rangle+\alpha_{h, 0}\left\|x_{h}\right\|^{2}+\sum_{i=1}^{N} \alpha_{h, i}\left\|T_{i}^{h} x_{h}\right\|^{2} \\
& =\alpha_{h, 0} \phi\left(w, x_{h}\right)+\sum_{i=1}^{N} \alpha_{h, i} \phi\left(w, T_{i}^{h} x_{h}\right) \\
& \leq \alpha_{h, 0} \phi\left(w, x_{h}\right)+\sum_{i=1}^{N} \alpha_{h, i} \phi\left(w, x_{h}\right)+\sum_{i=1}^{N} \alpha_{h, i} \xi_{h}
\end{aligned}
$$




$$
\begin{aligned}
& =\phi\left(w, x_{h}\right)+\sum_{i=1}^{N} \alpha_{h, i} \xi_{h} \\
& \leq \phi\left(w, x_{h}\right)+\sum_{i=1}^{N} \xi_{h},
\end{aligned}
$$

which shows that $w \in C_{h+1}$. This implies that $\bigcap_{i=1}^{N} F\left(T_{i}\right) \cap E F(f) \subset C_{n}$.

Next, we prove that the sequence $\left\{x_{n}\right\}$ is bounded. Notice that $x_{n}=\Pi_{C_{n}} x_{1}$. We find from Lemma 1.9 that $\left\langle x_{n}-z, J x_{1}-J x_{n}\right\rangle \geq 0$, for any $z \in C_{n}$. Since $\bigcap_{i=1}^{N} F\left(T_{i}\right) \cap E F(f) \subset C_{n}$, we find that

$$
\left\langle x_{n}-w, J x_{1}-J x_{n}\right\rangle \geq 0, \quad \forall w \in \bigcap_{i=1}^{N} F\left(T_{i}\right) \cap E F(f) .
$$

It follows from Lemma 1.8 that

$$
\begin{aligned}
\phi\left(x_{n}, x_{1}\right) & \leq \phi\left(\Pi_{\bigcap_{i=1}^{N} F\left(T_{i}\right) \cap E F(f)} x_{1}, x_{1}\right)-\phi\left(\Pi_{\bigcap_{i=1}^{N} F\left(T_{i}\right) \cap E F(f)} x_{1}, x_{n}\right) \\
& \leq \phi\left(\Pi_{\left.\bigcap_{i=1}^{N} F\left(T_{i}\right) \cap E F(f)^{x_{1}}, x_{1}\right) .}\right.
\end{aligned}
$$

This implies that the sequence $\left\{\phi\left(x_{n}, x_{1}\right)\right\}$ is bounded. It follows from (1.1) that the sequence $\left\{x_{n}\right\}$ is also bounded. Since the space is reflexive, we may assume, without loss of generality, that $x_{n} \rightarrow \bar{x}$. Next, we prove that $\bar{x} \in \bigcap_{i=1}^{N} F\left(T_{i}\right) \cap E F(f)$. Since $C_{n}$ is closed and convex, we find that $\bar{x} \in C_{n}$. This implies from $x_{n}=\Pi_{C_{n}} x_{1}$ that $\phi\left(x_{n}, x_{1}\right) \leq \phi\left(\bar{x}, x_{1}\right)$. On the other hand, we see from the weakly lower semicontinuity of $\|\cdot\|$ that

$$
\begin{aligned}
\phi\left(\bar{x}, x_{1}\right) & =\|\bar{x}\|^{2}-2\left\langle\bar{x}, J x_{1}\right\rangle+\left\|x_{1}\right\|^{2} \\
& \leq \liminf _{n \rightarrow \infty}\left(\left\|x_{n}\right\|^{2}-2\left\langle x_{n}, J x_{1}\right\rangle+\left\|x_{1}\right\|^{2}\right) \\
& =\liminf _{n \rightarrow \infty} \phi\left(x_{n}, x_{1}\right) \\
& \leq \limsup _{n \rightarrow \infty} \phi\left(x_{n}, x_{1}\right) \\
& \leq \phi\left(\bar{x}, x_{1}\right),
\end{aligned}
$$

which implies that $\lim _{n \rightarrow \infty} \phi\left(x_{n}, x_{1}\right)=\phi\left(\bar{x}, x_{1}\right)$. Hence, we have $\lim _{n \rightarrow \infty}\left\|x_{n}\right\|=\|\bar{x}\|$. In view of the Kadec-Klee property of $E$, we find that $x_{n} \rightarrow \bar{x}$ as $n \rightarrow \infty$. Since $x_{n}=\Pi_{C_{n}} x_{1}$, and $x_{n+1}=\Pi_{C_{n+1}} x_{1} \in C_{n+1} \subset C_{n}$, we find that $\phi\left(x_{n}, x_{1}\right) \leq \phi\left(x_{n+1}, x_{1}\right)$. This shows that $\left\{\phi\left(x_{n}, x_{1}\right)\right\}$ is nondecreasing. We find from its boundedness that $\lim _{n \rightarrow \infty} \phi\left(x_{n}, x_{1}\right)$ exists. It follows that

$$
\begin{aligned}
\phi\left(x_{n+1}, x_{n}\right) & =\phi\left(x_{n+1}, \Pi_{C_{n}} x_{1}\right) \\
& \leq \phi\left(x_{n+1}, x_{1}\right)-\phi\left(\Pi_{C_{n}} x_{1}, x_{1}\right) \\
& =\phi\left(x_{n+1}, x_{1}\right)-\phi\left(x_{n}, x_{1}\right) .
\end{aligned}
$$

This implies that

$$
\lim _{n \rightarrow \infty} \phi\left(x_{n+1}, x_{n}\right)=0 .
$$


In the light of $x_{n+1}=\Pi_{C_{n+1}} x_{1} \in C_{n+1}$, we find that

$$
\phi\left(x_{n+1}, u_{n}\right) \leq \phi\left(x_{n+1}, x_{n}\right)+\xi_{n} .
$$

It follows from (2.3) that

$$
\lim _{n \rightarrow \infty} \phi\left(x_{n+1}, u_{n}\right)=0
$$

In view of (1.1), we see that $\lim _{n \rightarrow \infty}\left(\left\|x_{n+1}\right\|-\left\|u_{n}\right\|\right)=0$. This implies that $\lim _{n \rightarrow \infty}\left\|u_{n}\right\|=$ $\|\bar{x}\|$. That is,

$$
\lim _{n \rightarrow \infty}\left\|J u_{n}\right\|=\lim _{n \rightarrow \infty}\left\|u_{n}\right\|=\|J \bar{x}\|
$$

This implies that $\left\{J u_{n}\right\}$ is bounded. Note that both $E$ and $E^{*}$ are reflexive. We may assume, without loss of generality, that $J u_{n} \rightarrow u^{*} \in E^{*}$. In view of the reflexivity of $E$, we see that $J(E)=E^{*}$. This shows that there exists an element $u \in E$ such that $J u=u^{*}$. It follows that

$$
\begin{aligned}
\phi\left(x_{n+1}, u_{n}\right) & =\left\|x_{n+1}\right\|^{2}-2\left\langle x_{n+1}, J u_{n}\right\rangle+\left\|u_{n}\right\|^{2} \\
& =\left\|x_{n+1}\right\|^{2}-2\left\langle x_{n+1}, J u_{n}\right\rangle+\left\|J u_{n}\right\|^{2} .
\end{aligned}
$$

Taking $\liminf _{n \rightarrow \infty}$ on both sides of the equality aboven yields

$$
\begin{aligned}
0 & \geq\|\bar{x}\|^{2}-2\left\langle\bar{x}, u^{*}\right\rangle+\left\|u^{*}\right\|^{2} \\
& =\|\bar{x}\|^{2}-2\langle\bar{x}, J u\rangle+\|J u\|^{2} \\
& =\|\bar{x}\|^{2}-2\langle\bar{x}, J u\rangle+\|u\|^{2} \\
& =\phi(\bar{x}, u) .
\end{aligned}
$$

That is, $\bar{x}=u$, which in turn implies that $u^{*}=J \bar{x}$. It follows that $J u_{n} \rightarrow J \bar{x} \in E^{*}$. Since $E^{*}$ enjoys the Kadec-Klee property, we obtain from (2.5) that $\lim _{n \rightarrow \infty} J u_{n}=J \bar{x}$. Since $J^{-1}$ : $E^{*} \rightarrow E$ is demicontinuous and $E$ enjoys the Kadec-Klee property, we obtain $u_{n} \rightarrow \bar{x}$, as $n \rightarrow \infty$. Note that

$$
\left\|x_{n}-u_{n}\right\| \leq\left\|x_{n}-\bar{x}\right\|+\left\|\bar{x}-u_{n}\right\|
$$

It follows that

$$
\lim _{n \rightarrow \infty}\left\|x_{n}-u_{n}\right\|=0
$$

Since $J$ is uniformly norm-to-norm continuous on any bounded sets, we have

$$
\lim _{n \rightarrow \infty}\left\|J x_{n}-J u_{n}\right\|=0 .
$$

On the other hand, we have

$$
\begin{aligned}
\phi\left(w, x_{n}\right)-\phi\left(w, u_{n}\right) & =\left\|x_{n}\right\|^{2}-\left\|u_{n}\right\|^{2}-2\left\langle w, J x_{n}-J u_{n}\right\rangle \\
& \leq\left\|x_{n}-u_{n}\right\|\left(\left\|x_{n}\right\|+\left\|u_{n}\right\|\right)+2\|w\|\left\|J x_{n}-J u_{n}\right\| .
\end{aligned}
$$


We, therefore, find that

$$
\lim _{n \rightarrow \infty}\left(\phi\left(w, x_{n}\right)-\phi\left(w, u_{n}\right)\right)=0 .
$$

Since $E$ is uniformly smooth, we know that $E^{*}$ is uniformly convex. In view of Lemma 1.11, we find that

$$
\begin{aligned}
\phi\left(w, u_{n}\right) & =\phi\left(w, S_{r_{n}} y_{n}\right) \\
& \leq \phi\left(w, y_{n}\right) \\
& =\phi\left(w, J^{-1}\left(\alpha_{n, 0} J x_{n}+\sum_{i=1}^{N} \alpha_{n, i} J T_{i}^{n} x_{n}\right)\right) \\
& =\|w\|^{2}-2\left(w, \alpha_{n, 0} J x_{n}+\sum_{i=1}^{N} \alpha_{n, i} J T_{i}^{n} x_{n}\right\rangle+\left\|\alpha_{n, 0} J x_{n}+\sum_{i=1}^{N} \alpha_{n, i} J T_{i}^{n} x_{n}\right\|^{2} \\
& \leq\|w\|^{2}-2 \alpha_{n, 0}\left\langle w, J x_{n}\right\rangle-2 \sum_{i=1}^{N} \alpha_{n, i}\left\langle w, J T_{i}^{n} x_{n}\right\rangle+\alpha_{n, 0}\left\|x_{n}\right\|^{2}+\sum_{i=1}^{N} \alpha_{n, i}\left\|T_{i}^{n} x_{n}\right\|^{2} \\
& -\alpha_{n, 0} \alpha_{n, 1} g\left(\left\|J x_{n}-J T_{1}^{n} x_{n}\right\|\right) \\
& =\alpha_{n, 0} \phi\left(w, x_{n}\right)+\sum_{i=1}^{N} \alpha_{n, i} \phi\left(w, T_{i}^{n} x_{n}\right)-\alpha_{n, 0} \alpha_{n, 1} g\left(\left\|J x_{n}-J T_{1}^{n} x_{n}\right\|\right) \\
& \leq \alpha_{n, 0} \phi\left(w, x_{n}\right)+\sum_{i=1}^{N} \alpha_{n, i} \phi\left(w, x_{n}\right)+\sum_{i=1}^{N} \alpha_{n, i} \xi_{h} \\
& -\alpha_{n, 0} \alpha_{n, 1} g\left(\left\|J x_{n}-J T_{1}^{n} x_{n}\right\|\right) \\
& =\phi\left(w, x_{n}\right)+\sum_{i=1}^{N} \alpha_{n, i} \xi_{n}-\alpha_{n, 0} \alpha_{n, 1} g\left(\left\|J x_{n}-J T_{1}^{n} x_{n}\right\|\right) \\
& \leq \phi\left(w, x_{n}\right)+\xi_{n}-\alpha_{n, 0} \alpha_{n, 1} g\left(\left\|J x_{n}-J T_{1}^{n} x_{n}\right\|\right) .
\end{aligned}
$$

It follows that

$$
\alpha_{n, 0} \alpha_{n, 1} g\left(\left\|J x_{n}-J T_{1}^{n} x_{n}\right\|\right) \leq \phi\left(w, x_{n}\right)-\phi\left(w, u_{n}\right)+\xi_{n} .
$$

In view of the restriction on the sequences, we find from (2.8) that $\lim _{n \rightarrow \infty} g\left(\| J x_{n}-\right.$ $\left.J T_{1}^{n} x_{n} \|\right)=0$. It follows that

$$
\lim _{n \rightarrow \infty}\left\|J x_{n}-J T_{1}^{n} x_{n}\right\|=0 .
$$

In the same way, we obtain

$$
\lim _{n \rightarrow \infty}\left\|J x_{n}-J T_{i}^{n} x_{n}\right\|=0, \quad \forall 1 \leq i \leq N .
$$

Notice that $\left\|J T_{i}^{n} x_{n}-J \bar{x}\right\| \leq\left\|J T_{i}^{n} x_{n}-J x_{n}\right\|+\left\|J x_{n}-J \bar{x}\right\|$. It follows that

$$
\lim _{n \rightarrow \infty}\left\|J T_{i}^{n} x_{n}-J \bar{x}\right\|=0 .
$$


The demicontinuity of $J^{-1}: E^{*} \rightarrow E$ implies that $T_{i}^{n} x_{n} \rightarrow \bar{x}$. Note that

$$
\left|\left\|T_{i}^{n} x_{n}\right\|-\|\bar{x}\|\right|=\left|\left\|J T_{i}^{n} x_{n}\right\|-\|J \bar{x}\|\right| \leq\left\|J T_{i}^{n} x_{n}-J \bar{x}\right\| .
$$

This implies from (2.9) that $\lim _{n \rightarrow \infty}\left\|T_{i}^{n} x_{n}\right\|=\|\bar{x}\|$. Since $E$ has the Kadec-Klee property, we obtain $\lim _{n \rightarrow \infty}\left\|T_{i}^{n} x_{n}-\bar{x}\right\|=0$. On the other hand, we have

$$
\left\|T_{i}^{n+1} x_{n}-\bar{x}\right\| \leq\left\|T_{i}^{n+1} x_{n}-T_{i}^{n} x_{n}\right\|+\left\|T_{i}^{n} x_{n}-\bar{x}\right\| .
$$

It follows from the uniformly asymptotic regularity of $T_{i}$ that

$$
\lim _{n \rightarrow \infty}\left\|T_{i}^{n+1} x_{n}-\bar{x}\right\|=0
$$

That is, $T_{i} T_{i}^{n} x_{n} \rightarrow \bar{x}$. From the closedness of $T_{i}$, we find $\bar{x}=T_{i} \bar{x}$ for every $1 \leq i \leq N$. This proves $\bar{x} \in \bigcap_{i=1}^{N} F\left(T_{i}\right)$.

Next, we show that $\bar{x} \in E F(f)$. In view of Lemma 1.8, we find that

$$
\begin{aligned}
\phi\left(u_{n}, y_{n}\right) & \leq \phi\left(w, y_{n}\right)-\phi\left(w, u_{n}\right) \\
& \leq \phi\left(w, x_{n}\right)+\mu_{n}-\phi\left(w, u_{n}\right) .
\end{aligned}
$$

It follows from (2.8) that $\lim _{n \rightarrow \infty} \phi\left(u_{n}, y_{n}\right)=0$. This implies that $\lim _{n \rightarrow \infty}\left(\left\|u_{n}\right\|-\left\|y_{n}\right\|\right)=0$. It follows from (2.6) that

$$
\lim _{n \rightarrow \infty}\left\|y_{n}\right\|=\|\bar{x}\|
$$

It follows that

$$
\lim _{n \rightarrow \infty}\left\|J y_{n}\right\|=\lim _{n \rightarrow \infty}\left\|y_{n}\right\|=\|\bar{x}\|=\|J \bar{x}\| .
$$

This shows that $\left\{y y_{n}\right\}$ is bounded. Since $E^{*}$ is reflexive, we may assume that $J y_{n} \rightarrow v^{*} \in E^{*}$. In view of $J(E)=E^{*}$, we see that there exists $v \in E$ such that $J v=v^{*}$. It follows that

$$
\begin{aligned}
\phi\left(u_{n}, y_{n}\right) & =\left\|u_{n}\right\|^{2}-2\left\langle u_{n}, J y_{n}\right\rangle+\left\|y_{n}\right\|^{2} \\
& =\left\|u_{n}\right\|^{2}-2\left\langle u_{n}, J y_{n}\right\rangle+\left\|J y_{n}\right\|^{2} .
\end{aligned}
$$

Taking $\liminf _{n \rightarrow \infty}$ the both sides of equality above yields that

$$
\begin{aligned}
0 & \geq\|\bar{x}\|^{2}-2\left\langle\bar{x}, v^{*}\right\rangle+\left\|v^{*}\right\|^{2} \\
& =\|\bar{x}\|^{2}-2\langle\bar{x}, J v\rangle+\|J v\|^{2} \\
& =\|\bar{x}\|^{2}-2\langle\bar{x}, J v\rangle+\|v\|^{2} \\
& =\phi(\bar{x}, v) .
\end{aligned}
$$

That is, $\bar{x}=v$, which in turn implies that $v^{*}=J \bar{x}$. It follows that $J y_{n} \rightarrow J \bar{x} \in E^{*}$. Since $E^{*}$ enjoys the Kadec-Klee property, we obtain $J y_{n}-J \bar{x} \rightarrow 0$ as $n \rightarrow \infty$. Note that $J^{-1}: E^{*} \rightarrow E$ 
is demicontinuous. It follows that $y_{n} \rightarrow \bar{x}$. Since $E$ enjoys the Kadec-Klee property, we obtain $y_{n} \rightarrow \bar{x}$ as $n \rightarrow \infty$. Note that

$$
\left\|u_{n}-y_{n}\right\| \leq\left\|u_{n}-\bar{x}\right\|+\left\|\bar{x}-y_{n}\right\| .
$$

This implies that $\lim _{n \rightarrow \infty}\left\|u_{n}-y_{n}\right\|=0$. Since $J$ is uniformly norm-to-norm continuous on any bounded sets, we have $\lim _{n \rightarrow \infty}\left\|J u_{n}-J y_{n}\right\|=0$. From the assumption $r_{n} \geq k$, we see that

$$
\lim _{n \rightarrow \infty} \frac{\left\|J u_{n}-J y_{n}\right\|}{r_{n}}=0 .
$$

Since $u_{n}=S_{r_{n}} y_{n}$, we find that

$$
f\left(u_{n}, y\right)+\frac{1}{r_{n}}\left\langle y-u_{n}, J u_{n}-J y_{n}\right\rangle \geq 0, \quad \forall y \in C .
$$

It follows from (A2) that

$$
\left\|y-u_{n}\right\| \frac{\left\|J u_{n}-J y_{n}\right\|}{r_{n}} \geq \frac{1}{r_{n}}\left\langle y-u_{n}, J u_{n}-J y_{n}\right\rangle \geq f\left(y, u_{n}\right), \quad \forall y \in C .
$$

In view of (A4), we find from (2.10) that

$$
f(y, \bar{x}) \leq 0, \quad \forall y \in C .
$$

For $0<t<1$ and $y \in C$, define $y_{t}=t y+(1-t) \bar{x}$. It follows that $y_{t} \in C$, which yields $f\left(y_{t}, \bar{x}\right) \leq 0$. It follows from (A1) and (A4) that

$$
0=f\left(y_{t}, y_{t}\right) \leq t f\left(y_{t}, y\right)+(1-t) f\left(y_{t}, \bar{x}\right) \leq t f\left(y_{t}, y\right) .
$$

That is,

$$
f\left(y_{t}, y\right) \geq 0
$$

Letting $t \downarrow 0$, we obtain from (A3) that $f(\bar{x}, y) \geq 0, \forall y \in C$. This implies that $\bar{x} \in E P(f)$.

Finally, we turn our attention to proving that $\bar{x}=\prod_{\bigcap_{i=1}^{N} F\left(T_{i}\right) \cap E F(f)} x_{1}$.

Letting $n \rightarrow \infty$ in (2.2), we obtain

$$
\left\langle\bar{x}-w, J x_{1}-J \bar{x}\right\rangle \geq 0, \quad \forall w \in \bigcap_{i=1}^{N} F\left(T_{i}\right) \cap E F(f) .
$$

In view of Lemma 1.9, we find that $\bar{x}=\prod_{\bigcap_{i=1}^{N} F\left(T_{i}\right) \cap E F(f)} x_{1}$. This completes the proof.

From the definition of quasi- $\phi$-nonexpansive mappings, we see that every quasi- $\phi$ nonexpansive mapping is asymptotically quasi- $\phi$-nonexpansive in the intermediate sense. We also know that every uniformly smooth and uniformly convex space is a uniformly smooth and strictly convex Banach space which also enjoys the Kadec-Klee property (note that every uniformly convex Banach space enjoys the Kadec-Klee property). 
Remark 2.2 Theorem 2.1 can be viewed an extension of the corresponding results in Qin et al. [6], Kim [12], Qin et al. [22], Takahashi and Zembayashi [24], respectively. The space $L^{p}$, where $p>1$, satisfies the restriction in Theorem 2.1.

\section{Applications}

Theorem 3.1 Let E be a uniformly smooth and strictly convex Banach space which also enjoys the Kadec-Klee property and let $C$ be a nonempty closed and convex subset of E. Let $f$ be a bifunction from $C \times C$ to $\mathbb{R}$ satisfying (A1)-(A4). Let $T: C \rightarrow C$ an asymptotically quasi- $\phi$-nonexpansive mapping in the intermediate sense. Assume that $T$ is closed asymptotically regular on $C$ and $F(T) \cap E F(f)$ is nonempty and bounded. Let $\left\{x_{n}\right\}$ be a sequence generated in the following manner:

$$
\left\{\begin{array}{l}
x_{0} \in E \text { chosen arbitrarily, } \\
C_{1}=C \\
x_{1}=\Pi_{C_{1} x_{0}} \\
y_{n}=J^{-1}\left(\alpha_{n, 0} J x_{n}+\alpha_{n, 1} J T^{n} x_{n}\right), \\
u_{n} \in C \text { such that } f\left(u_{n}, y\right)+\frac{1}{r_{n}}\left\langle y-u_{n}, J u_{n}-J y_{n}\right\rangle \geq 0, \quad \forall y \in C, \\
C_{n+1}=\left\{z \in C_{n}: \phi\left(z, u_{n}\right) \leq \phi\left(z, x_{n}\right)+\xi_{n}\right\}, \\
x_{n+1}=\Pi_{C_{n+1}} x_{0},
\end{array}\right.
$$

where $\xi_{n}=\max \left\{0, \sup _{p \in F(T), x \in C}\left(\phi\left(p, T^{n} x\right)-\phi(p, x)\right)\right\},\left\{r_{n}\right\}$ is a real number sequence in $[k, \infty)$, where $k$ is some positive real number, $\left\{\alpha_{n, 0}\right\}$ and $\left\{\alpha_{n} n, 1\right\}$ are two real number sequence in $(0,1)$. Assume that $\liminf _{n \rightarrow \infty} \alpha_{n, 0} \alpha_{n, 1}>0$. Then the sequence $\left\{x_{n}\right\}$ converges strongly to $\Pi_{F(T) \cap E F(f)} x_{1}$, where $\Pi_{F(T) \cap E F(f)}$ is the generalized projection from $E$ onto $F(T) \cap E F(f)$.

Proof Putting $N=1$, we draw from Theorem 2.1 the desired conclusion immediately.

Remark 3.2 If the mapping $T$ in Theorem 3.1 is quasi- $\phi$-nonexpansive, then the restrictions that $T$ is closed asymptotically regular on $C$ and $F(T) \cap E F(f)$ is bounded will not be required anymore.

If $T_{i}=I$, where $I$ is the identity for every $1 \leq i \leq N$, then we find from Theorem 2.1 the following.

Theorem 3.3 Let E be a uniformly smooth and strictly convex Banach space which also enjoys the Kadec-Klee property and let $C$ be a nonempty closed and convex subset of E. Let $f$ be a bifunction from $C \times C$ to $\mathbb{R}$ satisfying (A1)-(A4). Assume that $E F(f)$ is nonempty. Let 
$\left\{x_{n}\right\}$ be a sequence generated in the following manner:

$$
\left\{\begin{array}{l}
x_{0} \in E \text { chosen arbitrarily, } \\
C_{1}=C, \\
x_{1}=\Pi_{C_{1}} x_{0}, \\
u_{n} \in C \text { such that } f\left(u_{n}, y\right)+\frac{1}{r_{n}}\left\langle y-u_{n}, J u_{n}-J x_{n}\right\rangle \geq 0, \quad \forall y \in C, \\
C_{n+1}=\left\{z \in C_{n}: \phi\left(z, u_{n}\right) \leq \phi\left(z, x_{n}\right)\right\}, \\
x_{n+1}=\Pi_{C_{n+1}} x_{0},
\end{array}\right.
$$

where $\left\{r_{n}\right\}$ is a real number sequence in $[k, \infty)$, where $k$ is some positive real number. Then the sequence $\left\{x_{n}\right\}$ converges strongly to $\Pi_{E F(f)} x_{1}$, where $\Pi_{E F(f)}$ is the generalized projection from E onto $E F(f)$.

\section{Competing interests}

The authors declare that they have no competing interests.

\section{Authors' contributions}

Both authors contributed equally to this manuscript.

\section{Author details}

'School of Mathematics and Information Science, North China University of Water Resources and Electric Power, Zhengzhou, China. ${ }^{2}$ Basic Experimental \& Teaching Center, Henan University, Kaifeng, Henan, China.

\section{Acknowledgements}

The authors thank the reviewers for useful suggestions which improved the contents of this paper.

\section{Received: 29 January 2014 Accepted: 2 May 2014 Published: 22 May 2014}

\section{References}

1. Cioranescu, I: Geometry of Banach Spaces, Duality Mappings and Nonlinear Problems. Kluwer, Dordrecht (1990)

2. Alber, YI: Metric and generalized projection operators in Banach spaces: properties and applications. In: Kartsatos, AG (ed.) Theory and Applications of Nonlinear Operators of Accretive and Monotone Type. Dekker, New York (1996)

3. Reich, S: A weak convergence theorem for the alternating method with Bregman distance. In: Kartsatos, AG (ed.) Theory and Applications of Nonlinear Operators of Accretive and Monotone Type. Dekker, New York (1996)

4. Agarwal, RP, Qin, X, Cho, YJ: Generalized projection algorithms for nonlinear operators. Numer. Funct. Anal. Optim. 28, 1197-1215 (2007)

5. Su, Y, Qin, X: Strong convergence of modified Ishikawa iterations for nonlinear mappings. Proc. Indian Acad. Sci. Math. Sci. 117, 97-107 (2007)

6. Qin, X, Cho, YJ, Kang, SM: Convergence theorems of common elements for equilibrium problems and fixed point problems in Banach spaces. J. Comput. Appl. Math. 225, 20-30 (2009)

7. Qin, X, Cho, SY, Kang, SM: On hybrid projection methods for asymptotically quasi- $\phi$-nonexpansive mappings. Appl. Math. Comput. 215, 3874-3883 (2010)

8. Zhou, H, Gao, G, Tan, B: Convergence theorems of a modified hybrid algorithm for a family of quasi- $\phi$-asymptotically nonexpansive mappings. J. Appl. Math. Comput. 32, 453-464 (2010)

9. Qin, X, Wang, L: On asymptotically quasi- $\phi$-nonexpansive mappings in the intermediate sense. Abstr. Appl. Anal. 2012, Article ID 636217 (2012)

10. Kirk, WA: Fixed point theorems for non-Lipschitzian mappings of asymptotically nonexpansive type. Isr. J. Math. 17, 339-346 (1974)

11. Fan, K: A minimax inequality and applications. In: Shisha, O (ed.) Inequality III, pp. 103-113. Academic Press, New York (1972)

12. Kim, JK: Strong convergence theorems by hybrid projection methods for equilibrium problems and fixed point problems of the asymptotically quasi- $\boldsymbol{\phi}$-nonexpansive mappings. Fixed Point Theory Appl. 2011, Article ID 10 (2011)

13. Hao, Y: On generalized quasi- $\boldsymbol{\phi}$-nonexpansive mappings and their projection algorithms. Fixed Point Theory Appl. 2013, Article ID 204 (2013)

14. Cho, SY, Qin, X: On the strong convergence of an iterative process for asymptotically strict pseudocontractions and equilibrium problems. Appl. Math. Comput. 235, 430-438 (2014)

15. Zhang, QN: Common solutions of equilibrium and fixed point problems. J. Inequal. Appl. 2013, Article ID 425 (2013)

16. Chang, SS, Chan, CK, Lee, HWJ: Modified block iterative algorithm for quasi- $\phi$-asymptotically nonexpansive mappings and equilibrium problem in Banach space. Appl. Math. Comput. 217, 7520-7530 (2011)

17. Chang, SS, Lee, HWJ, Chan, CK: A new hybrid method for solving a generalized equilibrium problem, solving a variational inequality problem and obtaining common fixed points in Banach spaces, with applications. Nonlinear Anal. 73, 2260-2270 (2010) 
18. Yang, S, Zhang, MY: Strong convergence theorems for fixed points of generalized asymptotically quasi- $\boldsymbol{\phi}$-nonexpansive mappings. Adv. Fixed Point Theory 4, 69-90 (2014)

19. Chen, JH: Iterations for equilibrium and fixed point problems. J. Nonlinear Funct. Anal. 2013, Article ID 4 (2013)

20. Qin, X, Su, Y: Strong convergence theorems for relatively nonexpansive mappings in a Banach space. Nonlinear Anal. 67, 1958-1965 (2007)

21. Yang, L, Zhao, F, Kim, JK: Hybrid projection method for generalized mixed equilibrium problem and fixed point problem of infinite family of asymptotically quasi- $\phi$-nonexpansive mappings in Banach spaces. Appl. Math. Comput. $218,6072-6082(2012)$

22. Qin, X, Cho, SY, Kang, SM: Strong convergence of shrinking projection methods for quasi- $\phi$-nonexpansive mappings and equilibrium problems. J. Comput. Appl. Math. 234, 750-760 (2010)

23. Wu, C, LV, S: Bregman projection methods for zeros of monotone operators. J. Fixed Point Theory 2013, Article ID 7 (2013)

24. Takahashi, W, Zembayashi, K: Strong and weak convergence theorems for equilibrium problems and relatively nonexpansive mappings in Banach spaces. Nonlinear Anal. 70, 45-57 (2009)

25. Qin, X: A regularization method for treating zero points of the sum of two monotone operators. Fixed Point Theory Appl. 2014, Article ID 75 (2014)

26. Yuan, Q: Some results on asymptotically quasi- $\phi$-nonexpansive mappings in the intermediate sense. J. Fixed Point Theory 2012, Article ID 1 (2012)

27. Cho, SY: Strong convergence of a splitting algorithm for treating monotone operators. Fixed Point Theory Appl. 2014 Article ID $94(2014)$

28. Wang, S, Zhou, C: New iterative scheme for finite families of equilibrium, variational inequality, and fixed point problems in Banach spaces. Fixed Point Theory Appl. 2011, Article ID 372975 (2011)

29. Zhang, C, Li, J, Liu, B: Strong convergence theorems for equilibrium problems and relatively nonexpansive mappings in Banach spaces. Comput. Math. Appl. 61, 262-276 (2011)

30. Cho, SY, Kang, SM: Approximation of common solutions of variational inequalities via strict pseudocontractions. Acta Math. Sci. 32, 1607-1618 (2012)

31. Qin, X, Agarwal, RP: Shrinking projection methods for a pair of asymptotically quasi- $\boldsymbol{\phi}$-nonexpansive mappings. Numer. Funct. Anal. Optim. 31, 1072-1089 (2010)

32. Zhang, M: An algorithm for treating asymptotically strict pseudocontractions and monotone operators. Fixed Point Theory Appl. 2014, Article ID 52 (2014)

33. Qing, Y, LV, S: A strong convergence theorem for solutions of equilibrium problems and asymptotically quasi- $\phi$-nonexpansive mappings in the intermediate sense. Fixed Point Theory Appl. 2013, Article ID 305 (2013)

34. Wang, W, Song, J: Hybrid projection methods for a bifunction and relatively asymptotically nonexpansive mappings. Fixed Point Theory Appl. 2013, Article ID 294 (2013)

35. Zălinescu, C: On uniformly convex functions. J. Math. Anal. Appl. 95, 344-374 (1983)

10.1186/1029-242X-2014-202

Cite this article as: Huang and Ma: Some results on asymptotically quasi- $\phi$-nonexpansive mappings in the intermediate sense and equilibrium problems. Journal of Inequalities and Applications 2014, 2014:202

\section{Submit your manuscript to a SpringerOpen ${ }^{\circ}$ journal and benefit from:}

- Convenient online submission

- Rigorous peer review

- Immediate publication on acceptance

- Open access: articles freely available online

- High visibility within the field

- Retaining the copyright to your article 